\title{
Prevalence of congenital heart defect in Guangdong province, 2008-2012
}

\author{
$\mathrm{Li} \mathrm{Wu}^{1 \dagger}$, Bing $\mathrm{Li}^{1 \dagger}$, Jianhong Xia ${ }^{1}$, Cunwei $\mathrm{Ji}^{1}$, Zhijiang Liang${ }^{1}$, Yuanzhu Ma', Shiyun Li', Yuntao Wu', \\ Youjie Wang ${ }^{2}$ and Qingguo Zhao ${ }^{1 *}$
}

\begin{abstract}
Background: Congenital heart defect (CHD) is the most common major malformations in infants. Little is known about the main epidemiologic characteristics of CHD prevalence in Guangdong province, China. Our study was undertaken to investigate the time trends in the prevalence of CHD in Guangdong province from 2008 to 2012.

Methods: Data were retrieved from the Guangdong Hospital-Based Birth Defects Monitoring System during 2008-2012. All infants more than 28 weeks of gestation and infants up to 7 days of age in monitoring hospitals were monitored. We used prevalence rate to describe the difference in prevalence of CHD between rural and urban areas. Odds ratio (OR) and 95\% confidence interval (Cl) for CHD were calculated for the rural and urban areas. The CHD rate was calculated on the basis of birth defects per 10,000 births.

Results: A total of 1005052 births were reported to the Birth Defects Monitoring Network of Guangdong Province, of which 5268 cases were diagnosed as CHD. The overall prevalence of CHD was 52.41 per 10000 births (95\% Cl: $51.00 \sim 53.83$ ) in provincial-wide, 66.08 per 10000 births (95\% Cl: 63.77 68.39) in urban areas, and 40.23 per 10000 births (95\% Cl: $38.52 \sim 41.93)$ in rural areas. The prevalence of $\mathrm{CHD}$ increased with maternal age both in urban areas $(P<0.01)$ and in rural areas $(P<0.01)$.
\end{abstract}

Conclusion: The increasing trends of CHD prevalence suggest that maternal age and the improvement of diagnosis ability might play a critical role.

Keywords: Birth defects, Congenital heart defect, Prevalence

\section{Background}

Birth defects are the main causes of early miscarriage, perinatal death, infant death and child disabilities, which have been a global public health issue [1]. Congenital heart defects (CHD) is the most common type of birth defects $[2,3]$, with a wide range of reported birth prevalence estimates. It is the leading cause of infant mortality and morbidity [4-6] associated with birth defects and can result in chronic disability and increased health care costs $[7,8]$.

Epidemiological studies in developed countries have indicated that a prevalence of CHD ranged from 4-10 per 1000 live births $[3,9,10]$. The prevalence of CHD among fetuses is estimated to be even higher, at 14.6 per 1000 fetuses [11]. Complex CHD is common among fetuses [12] and may result in spontaneous abortion or stillbirth, the

\footnotetext{
*Correspondence: 1693910767@qq.com

${ }^{\dagger}$ Equal contributors

'Guangdong Women and Children Hospital, Guangzhou, China

Full list of author information is available at the end of the article
}

total prevalence of CHD among stillbirths and live births may be higher than that reported among live births alone.

The prevalence of CHD has been studied in developed countries for many years $[3,4]$, and it is also studied in the mainland of China [13,14]. However, little is known about the main epidemiologic characteristics of CHD prevalence in Guangdong province. This study was done using the Hospital-Based Birth Defect Surveillance System of Guangdong Province, China. We analyzed the prevalence and characteristics of CHD in perinatal infants in Guangdong province during 2008-2012, in order to provide a scientific basis for developing control measures over prevention of CHD on perinatal infants (from 28 weeks of gestation to a period of 7 days after delivery).

\section{Methods}

Data were obtained from the Birth Defects Monitoring Network of Guangdong Province from 2008 to 2012.

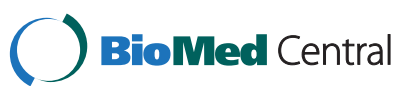


The monitoring system is hospital-based registry covering 58 hospitals across the province, and the hospitals at the county level or above were selected to participate. The program primarily monitors infants with birth defects who are born in hospitals. The subjects monitored by the network included live births and stillbirths who were delivered in hospital after at least 28 weeks of gestation. The clinical diagnosis of CHD was diagnosed within 7 days after delivery. Within this period, all diagnosed birth defects were required to be reported. The CHD was identified according to the International Classification of Diseases Clinical Modification Codes, tenth edition (i.e., ICD-10).

CHD was defined as "a gross structural abnormality of the heart or intrathoracic great vessels that is actually or potentially of functional importance [13]. An isolated patent foramen ovale and patent ductus arteriosus were excluded because they are normal findings in perinatal infants.

\section{Data collection and quality management}

A registration form for birth defect cases was used to collect information for $\mathrm{CHD}$ cases. In the monitoring hospitals, the health care professionals examined every infant immediately after birth to screen for CHD. The diagnosis and verification must be completed within 7 days after delivery. For those affected by CHD, an inperson interview with the mother and medical record reviews were conducted to gather information by a trained doctor. The information is collected using a standard birth defects registration form. The data about deliveries, the number of perinatal infants, and sex of infants are collected using the Seasonal Report Form. The county-level staff submits the forms using the web-based data reporting system. The forms are checked by senior who are responsible for data quality in the monitoring hospital. When errors were identified, the form should be returned for verification. The monitors at the municipal and provincial levels should check the forms. Finally, the data was sent to the National Center for Birth Defects Monitoring (national center level), where the experts were responsible for the final confirmation of diagnosis, data checking and evaluating, and disease coding, etc. Because our data was obtained from the database of the Birth Defects Monitoring Network of Guangdong Province, and the data was de-identified and analyzed anonymously, our ethics committee waived the need for informed consent. We received permission from the Birth defects Intervention Group of Guangdong Province to use the data.

\section{Statistical analysis}

Residential areas were categorized into rural and urban areas according to mother's residence address during the pregnancy. The number of deliveries in the hospital after at least 28 weeks' gestation was used as the denominator, and the number of infants diagnosed with CHD within 7 days of birth was used as the numerator. Prevalence estimates are reported per 10000 live births. We used Poisson distribution to calculate 95\% CI of CHDs and its subtypes prevalence. Prevalence rate was used to describe the type-specific difference between urban and rural areas. The significance of categorical variables was assessed by a $X^{2}$ test or Fisher exact test. We used CochranArmitage trend test for analysis of trend. Odd ratio (OR) was presented. All ORs were calculated relative to rural areas. A probability value of $P<0.05$ was regarded as significant. Statistical analysis was conducted using SPSS for Windows version 13.0.

\section{Results}

\section{Demographic characteristics}

Between 2008 and 2012, a total of 1005052 deliveries were reported to the Birth Defects Monitoring Network of Guangdong Province, of which 5268 cases were diagnosed as CHD. Baseline demographic characteristics of infants with $\mathrm{CHD}$ and their mothers are presented in Table 1.

\section{Birth prevalence}

The overall birth prevalence of CHD was 52.41 per 10 000 births (95\% CI: $51.00 \sim 53.83)$ in provincial-wide,

Table 1 Demographic characteristics of perinatals with CHD and their mothers in Guangdong, China, 2008-2012

\section{Characteristics}

\begin{tabular}{lc}
\hline Maternal age, $\mathbf{y}$ & $28.19 \pm 4.92$ \\
Education & \\
Illiterate & $29(0.55 \%)$ \\
$1 \sim 6$ years & $172(3.26 \%)$ \\
$7 \sim 9$ years & $1771(33.62 \%)$ \\
$10 \sim 12$ years & $1939(36.81 \%)$ \\
$13 \sim 16$ years & $1347(25.57 \%)$ \\
Unknown & $10(0.19 \%)$ \\
Gestational age (week) & \\
$<37$ & $1841(34.95 \%)$ \\
$\geq 37$ & $3427(65.05 \%)$ \\
Fetal sex & \\
Male & $2975(56.47 \%)$ \\
Female & $2649(43.30 \%)$ \\
Unknown & $76(0.23 \%)$ \\
Birth weight (g) & $2748.00 \pm 795.15$ \\
Fetal number & \\
Singleton & $4979(94.51 \%)$ \\
Twin & $303(5.30 \%)$ \\
Multi-fetal & $10(0.19 \%)$ \\
\hline Da a expres
\end{tabular}

Data are expressed as mean \pm standard deviation or no. (\%). 
Table 2 Time trends in the prevalence of CHD (per 10000 births) by rural-urban residence in Guangdong province, China, 2008-2012

\begin{tabular}{|c|c|c|c|c|c|c|c|}
\hline \multirow[t]{2}{*}{ Year } & \multicolumn{3}{|c|}{ Urban } & \multicolumn{3}{|c|}{ Rural } & \multirow{2}{*}{$\begin{array}{l}\text { Urban-rural } \\
\text { rate ratio }\end{array}$} \\
\hline & Birth & Cases & Prevalence $(95 \% \mathrm{Cl})$ & Birth & Cases & Prevalence $(95 \% \mathrm{Cl})$ & \\
\hline 2008 & 83433 & 495 & $59.33(54.12 \sim 64.54)$ & 92131 & 251 & $27.24(23.88 \sim 30.61)$ & 2.18 \\
\hline 2009 & 85413 & 405 & $47.42(42.81 \sim 52.02)$ & 97558 & 236 & $24.19(21.11 \sim 27.27)$ & 1.96 \\
\hline 2010 & 92701 & 351 & 37.86 (33.91 41.82) & 100417 & 373 & $37.14(33.38 \sim 40.91)$ & 1.02 \\
\hline 2011 & 97024 & 638 & $65.76(60.67 \sim 70.84)$ & 112746 & 386 & $34.23(30.83 \sim 37.64)$ & 1.92 \\
\hline 2012 & 115238 & 1242 & $107.78(101.82$ 113.74) & 128391 & 891 & $69.40(64.86 \sim 73.94)$ & 1.55 \\
\hline 2008-2012 & 473809 & 3131 & 66.08 (63.77 68.39) & 531243 & 2137 & $40.23(38.52 \sim 41.93)$ & 1.64 \\
\hline
\end{tabular}

Note: $\mathrm{Cl}=$ Confidence interval.

66.08 per 10000 births (95\% CI: $63.77 \sim 68.39)$ in urban areas, and 40.23 per 10000 births (95\% CI: $38.52 \sim 41.93)$ in rural areas.

The birth prevalence of CHD in urban areas increased from 59.33 per 10000 urban births in 2008 to 107.78 per 10000 urban births in 2012. In rural areas, the birth prevalence increased from 27.24 per 10000 births in 2008 to 69.40 per 10000 births in 2012. The results were shown in Table 2.

Maternal age was divided into five different age groups: <20 years, 20-24 years, 25-29 years, 30-34 years and $\geq 35$ years. The birth prevalence of CHD increased with maternal age both in urban areas $(P<0.01)$ and in rural areas $(P<0.01)$. The results were shown in Table 3 .

\section{Discussion}

CHD is the most common group of congenital anomalies and a major cause of death in infancy and childhood [15]. They are frequently required multiple hospitalizations and surgical procedures. Our study examined the epidemiologic features of CHD, using the data from the Guangdong Hospital-Based Birth Defects Monitoring System. We provide birth prevalence for CHD. In our study, all live births and still births born in monitoring hospitals were included and accessed within 7 days after delivery. So the prevalence of CHD in our study reflects the perinatal prevalence of CHD.
Our results showed that the prevalence rises in urban and rural populations during 2008-2012. There are might three reasons for that. First, the use of ultrasonic examination makes the rate of congenital diagnosis improved. In the lack of ultrasonic examination, the percentage of CHD was lower [16]. In our study, we also found that the use of ultrasonic examination rises during 2008-2012 (data not shown). Second, with the improvement of congenital diagnosis, more and more CHD cases can be found in the perinatal period, resulting in an increasing prevalence. Parents accepted cardiac echocardiography as the most important neonatal screening method, and they were willing to screen their babies with cardiac echocardiography to determine whether CHD were present. Third, environmental and genetic factors can influence the prevalence of CHD.

The difference of maternal age-specific overall prevalence was observed in our study, and the prevalence in urban and rural areas increased with maternal age. A similar finding has been reported by Miller et al. [17], who reported that the prevalence in infants born to mothers older than 35 years was much higher than in those born to younger mothers. Other studies have showed that the prevalence of CHD increases with increasing maternal age $[14,18,19]$.

In the birth defect registry system, the urban-rural classification depends on the place where the mother lived during the pregnancy, which mainly reflects the combined

Table 3 Maternal age-specific disparity of prevalence of CHD between rural and urban areas in Guangdong, 2008-2012

\begin{tabular}{|c|c|c|c|c|c|c|c|c|c|}
\hline \multirow[t]{2}{*}{ Age } & \multicolumn{3}{|c|}{ Urban } & \multicolumn{3}{|c|}{ Rural } & \multicolumn{3}{|c|}{ Provincial } \\
\hline & Cases & Prevalence $^{a}$ & $95 \% \mathrm{Cl}$ & Cases & Prevalence $^{b}$ & $95 \% \mathrm{Cl}$ & Cases & Prevalence $^{c}$ & $95 \% \mathrm{Cl}$ \\
\hline$<20$ & 33 & 47.37 & $31.24 \sim 63.49$ & 49 & 32.27 & $23.24 \sim 41.29$ & 82 & 37.02 & $29.02 \sim 45.02$ \\
\hline $20-$ & 547 & 57.49 & $52.68 \sim 62.29$ & 571 & 39.16 & $35.96 \sim 42.37$ & 1118 & 46.40 & $43.69 \sim 49.11$ \\
\hline $25-$ & 1365 & 63.19 & $59.85 \sim 66.53$ & 845 & 37.59 & $35.06 \sim 40.12$ & 2210 & 50.14 & $48.05 \sim 52.22$ \\
\hline $30-$ & 811 & 72.99 & $67.99 \sim 78.00$ & 447 & 43.59 & $39.56 \sim 47.62$ & 1258 & 58.88 & $55.64 \sim 62.13$ \\
\hline$\geq 35$ & 375 & 84.13 & $75.65 \sim 92.60$ & 225 & 52.40 & $45.57 \sim 59.23$ & 600 & 68.56 & $63.09 \sim 74.03$ \\
\hline
\end{tabular}

Note: Note: $\mathrm{Cl}=$ Confidence interval.

Prevalence trend was tested by Cochran-Armitage trend test

${ }^{\mathrm{a}} \mathrm{Z}=-5.99, P<0.01 ;{ }^{\mathrm{b}} \mathrm{Z}=-3.86, P<0.01{ }^{\mathrm{c}} \mathrm{Z}=-8.70, P<0.01$. 
exposure during the pregnancy $[18,20]$. In our study, we found a higher prevalence in urban areas compared with rural areas. The education, economic level, occupational exposure, lifestyle, and health care are different between people who live in urban and rural areas in China [21,22]. On the other hand, living in rural areas may be associated with lower access to health care and a shortage of healthcare providers. The prevalence of CHD subtypes were also found to vary by urban-rural classification.

The data of our study is reliable and representative. The study was based on the birth defect registry system of the province of Guangdong, and the system contains 58 hospitals covering districts, which represents the total situation of CHD in Guangdong province well. All data were reported on the network in time. Strict quality control of data collection was taken by county, municipal and provincial experts every year, thus ensuring reliable data. However, several limitations in the study should be addressed. First, according to the surveillance system, the monitoring period was 28 weeks' gestation to 6 days after delivery, and babies with CHD detected more than 7 days after delivery would be missed. Second, the study did not cover cases of births given out of hospital, although the proportion was small. Third, our study was difficulty in distinguishing between an ASD and a patent foramen ovale in the perinatal period. And because of most of foramen ovale and ductus arteriosus after birth to 6 days is normally patent and will be closed naturally within several months. The exclusion of a patent foramen ovale and patent ductus arteriosus in perinatal infants eliminated perinatal conditions from consideration, thereby improving the prevalence estimates of CHD. Finally, it is possible that hospital-based samples might introduce referral bias. However, our study used the data from the Guangdong Hospital-Based Birth Defects Monitoring System, which is covering 58 hospitals across the province, and our results provide value insights to our understanding of the main epidemiologic characteristics of CHD prevalence in Guangdong province.

The findings from our study have some practical implications. High prevalence of CHD indicates that CHD become one of the major public health concerns in Guangdong province, China. A high and increasing rate of $\mathrm{CHD}$ among perinatal infants increases the burden on families and health care providers, both in terms of parental anxiety, and of the direct costs of diagnostic examinations, follow-up, and possibly treatment [17].

\section{Conclusions}

In conclusion, the birth prevalence of CHD increased from 2008 to 2012 both in urban and rural areas. The increasing trends of $\mathrm{CHD}$ prevalence suggest that maternal age and the improvement of diagnosis ability might play a critical role. More comprehensive surveillance among infants would improve prevalence rate for $\mathrm{CHD}$ and help assess prevention efforts, and knowing the prevalence and distribution of CHD can help pediatricians and public health professionals better assess health care needs and conduct causal research.

\section{Competing interests}

The authors have declared that no competing interests exist.

\section{Authors' contributions}

$\mathrm{QZ}$ and BL designed the study and performed the analysis. SL and YM collected the data. ZL, TC and CJ assisted in the analysis and data interpretation. LW drafted the manuscript. JX and YW reviewed and refined the manuscript. All authors read and approved the final manuscript.

\section{Acknowledgements}

We thank all staff members involved in birth defects monitoring in the province of Guangdong.

\section{Author details}

${ }^{1}$ Guangdong Women and Children Hospital, Guangzhou, China. ${ }^{2}$ Department of Maternal and Child health, School of Public Health, Tongji Medical College, Huazhong University of Science and Technology, Wuhan, China.

Received: 14 July 2013 Accepted: 10 February 2014

Published: 11 February 2014

\section{References}

1. Dai L, Zhu J, Liang J, Wang YP, Wang H, Mao M: Birth defects surveillance in China. World J Pediatr 2011, 7(4):302-310.

2. Correa A, Cragan JD, Kucik JE, Alverson CJ, Gilboa SM, Balakrishnan R, et al: Reporting birth defects surveillance data 1968-2003. Birth Defects Res A Clin Mol Teratol 2007, 79(2):65-186.

3. Reller MD, Strickland MJ, Riehle-Colarusso T, Mahle WT, Correa A: Prevalence of congenital heart defects in metropolitan Atlanta, 1998-2005. J Pediatr 2008, 153(6):807-813.

4. Boneva RS, Botto LD, Moore CA, Yang Q, Correa A, Erickson JD: Mortality associated with congenital heart defects in the United States: trends and racial disparities, 1979-1997. Circulation 2001, 103(19):2376-2381.

5. Cleves MA, Ghaffar S, Zhao W, Mosley BS, Hobbs CA: First-year survival of infants born with congenital heart defects in Arkansas (1993-1998): a survival analysis using registry data. Birth Defects Res A Clin Mol Teratol 2003, 67(9):662-668.

6. Yang Q, Chen H, Correa A, Devine O, Mathews TJ, Honein MA: Racial differences in infant mortality attributable to birth defects in the United States, 1989-2002. Birth Defects Res A Clin Mol Teratol 2006, 76(10):706-713.

7. Centers for Disease Control and Prevention: Hospital stays, hospital charges, and in-hospital deaths among infants with selected birth defects-United States, 2003. MMWR Morb Mortal Wkly Rep 2007, 56(2):25-29.

8. Waitzman NJ, Romano PS, Scheffler RM: Estimates of the economic costs of birth defects. Inquiry 1994, 31(2):188-205.

9. Moons P, Sluysmans T, De Wolf D, Massin M, Suys B, Benatar A, Gewillig M: Congenital heart disease in 111225 births in Belgium: birth prevalence, treatment and survival in the 21st century. Acta Paediatr 2009, 98(3):472-477.

10. Shah GS, Singh MK, Pandey TR, Kalakheti BK, Bhandari GP: Incidence of congenital heart disease in tertiary care hospital. Kathmandu Univ Med J (KUMJ) 2008, 6(1):33-36.

11. Tegnander E, Williams W, Johansen OJ, Blaas HG, Eik-Nes SH: Prenatal detection of heart defects in a non-selected population of 30,149 fetuses-detection rates and outcome. Ultrasound Obstet Gynecol 2006, 27(3):252-265.

12. Tennstedt C, Chaoui R, Korner H, Dietel M: Spectrum of congenital heart defects and extracardiac malformations associated with chromosomal abnormalities: results of a seven year necropsy study. Heart 1999, 82(1):34-39

13. Zhang Y, Riehle-Colarusso T, Correa A, Li S, Feng X, Gindler J, et al: Observed prevalence of congenital heart defects from a surveillance study in China. J Ultrasound Med 2011, 30(7):989-995.

14. Zhu J, Zhou X, Dai L, Wang Y, Liang J, Miao L: The prevalence analysis of congenital heart disease in Chinese perinatals: 1996-2000. J Sichuan Univ 2004, 35(6):875-877 
15. Hoffman Jl, Kaplan S: The incidence of congenital heart disease. J Am Coll Cardiol 2002, 39(12):1890-1900.

16. Garne E, Stoll C, Clementi M: Evaluation of prenatal diagnosis of congenital heart diseases by ultrasound: experience from 20 European registries. Ultrasound Obstet Gynecol 2001, 17(5):386-391.

17. Miller A, Riehle-Colarusso T, Siffel C, Frias JL, Correa A: Maternal age and prevalence of isolated congenital heart defects in an urban area of the United States. Am J Med Genet A 2011, 155A(9):2137-2145.

18. Dai L, Zhu J, Zhou G, Wang Y, Miao L: The monitoring of cleft lip with or without cleft palate in China: 1996-2000. Zhonghua Kou Qiang Yi Xue Za Zhi 2003, 38(6):438-440.

19. Shu L, Qu Y, Yang X: The detection and prenatal diagnosis of congenital heart disease from 2008 to 2010 in Ningbo district. Chin J Birth Health Heredity 2012, 20(1):78-79.

20. Dai L, Miao L, Zhou GX, Zhu J, Li G: The prevalence analysis of cleft palate in Chinese perinatals: 1996-2000. Hua Xi Kou Qiang Yi Xue Za Zhi 2004, 22(1):35-37.

21. Shi L: Health care in China: a rural-urban comparison after the socioeconomic reforms. Bull World Health Organ 1993, 71(6):723-736.

22. Tang S, Meng Q, Chen L, Bekedam H, Evans T, Whitehead M: Tackling the challenges to health equity in China. Lancet 2008, 372(9648):1493-1501.

doi:10.1186/1471-2458-14-152

Cite this article as: Wu et al:: Prevalence of congenital heart defect in Guangdong province, 2008-2012. BMC Public Health 2014 14:152.

\section{Submit your next manuscript to BioMed Central and take full advantage of:}

- Convenient online submission

- Thorough peer review

- No space constraints or color figure charges

- Immediate publication on acceptance

- Inclusion in PubMed, CAS, Scopus and Google Scholar

- Research which is freely available for redistribution 